\title{
Cryomazine concentration and host type effects on the biology of the southern cowpea weevil Callosobruchus maculatus $\mathrm{F}$.
}

\author{
Fahd Abdu Al-Mekhlafi ${ }^{1}$, Ashraf Mohamed Ali Mashaly ${ }^{1,2 *}$, Mohamed Ahmed Wadaan ${ }^{1}$ \\ and Nazar M. Al-Mallah ${ }^{3}$ \\ ${ }^{1}$ Department of Zoology, College of Science, P. O. Box 2455, King Saud University, Riyadh 11451, \\ Kingdom of Saudi Arabia. \\ ${ }^{2}$ Department of Zoology, Faculty of Science, Minia University, El-Minia, Egypt. \\ ${ }^{3}$ Plant Protection Department, College of Agriculture and Forestry, Mosul University, Mosul, Iraq.
}

Accepted 30 July, 2011

\begin{abstract}
In this study we investigated the effects of different cryomazine concentrations and host type on the biology of the southern cowpea weevil Callosobruchus maculatus F. (Coleoptera: Bruchidae). Our results showed that increasing cryomazine concentration led to the increase in the average incubation period of eggs and low hatching rate, reaching the highest average of egg incubation period 13.25 days for insects reared on a mung beans treated with cryomazine concentration of 3 and $5 \%$. The lowest average for incubation period reached 9.25 days when insects reared on cowpea treated with $1 \%$ concentration of cryomazine. Insect reared on peas treated with $5 \%$ cryomazine concentration had a lower average percentage of hatching eggs, $1.25 \%$ in comparison with the control $(67.25 \%)$. The maximum average rate of eggs hatching reached $55 \%$ of insects reared on mung beans treated with $1 \%$ cryomazine concentration compared with the control (75\%). High cryomazine concentration reduced the percentage of pupation and adult emergence; the average percentage reached 19.83 and $27.08 \%$, compared with the control $\mathbf{8 7 . 3 3}$ and $\mathbf{8 8 . 5 \%}$ respectively. Thus, increasing cryomazine concentration not only led to the increase in the average duration of larvae and pupae of insects bred to all nutritional hosts except peas where the insect was unable to complete its life cycle but also led to reduction in the percentage of pupation and adult emergence.
\end{abstract}

Key words: Adult emergence, egg hatchability, insect growth regulating (IGR), incubation period, Trigard.

\section{INTRODUCTION}

Seed beetles of the genus Callosobruchus (Coleoptera: Bruchidae) are economically important pests of stored legumes (Labeyrie, 1981; Fujii et al., 1990). The southern cowpea weevil, Callosobruchus chinensis, is a major pest of stored legumes in warm temperate and tropical climates. C. maculatus was reported in different countries around the world (El-Sayed and Kamel, 1978; Saplina, 1980; Singh and Srivastava, 1980; Haines, 1981; Credland and Dick, 1987). The ability of the adult insects

*Corresponding author. E-mail: mmashely@ksu.edu.sa. Fax: +96614678514. of this pest to fly facilitates its transition from the store to the field and vice versa. Crop damage caused by feeding of insect larvae on the growing seeds and this damage increased when the larvae continue to grow up where consume more huge contents of seeds (Howe and Currie, 1964; Pajni, 1965; Elazawe et al., 1990). The southern cowpea weevil has the capability to infest not only cultivated host plants in the field and stored legumes but also a few wild legumes (Shinoda and Yoshida, 1985, 1990; Shinoda et al., 1991, 1992; Tuda et al., 2005).

There are concerns with the use of synthetic chemicals to control stored-product insects; presence of residues in food, resistance development by pest species, health risks (Arthur, 1996), increased cost (Hagstrum and 
Subramanyam, 2006) and toxicity to non-target organisms (Fields, 1992). Insect growth regulating (IGR) may adversely affect insects by regulating or inhibiting specific biochemical pathways or processes essential for insect growth and development. More importantly, insect growth regulators were considered to be better used in an integrated pest management program, rather than being used alone (Oberlander et al., 1997). Vazirianzadeh et al. (2007) concluded that cyromazine should be used in a larvicidal program to control housefly. Females of the southern pine beetle Dendroctonus frontalis Zim are porn to sterility more than males when treated with sub-lethal doses of chemical sanitizers such as Thiotepa and Hempa 31 and insect growth inhibitors such as Diflubenzuron and Penfluron (Richmond et al., 1978).

Seven insecticides were used against $C$. maculatus and it was found that many of the organophosphorus pesticides such as Chlorpyrifosmethyl, Fenitrothion, Methecrifos and Pirimiphos-methyl had lost their impact in a short period of storage compared with Fenoxycarb (Daglish et al., 1993). Exposure of adult insects of $C$. maculatus to $700 \mathrm{ppm}$ concentration of Diflubenzuron resulted in a series of deleterious events; death of $88 \%$ of the insects, decreased in the number of eggs, absence of wings in the first and second generation and decreased in the lifespan of adults (Khallak, 1990). Cowpea seeds Vigna radiata (valety Ps-16) treated with concentration $0.02 \mathrm{~g} /$ active ingredient/ $\mathrm{kg}$ of Diflubenzuron, Triflumuron, Flucycloxuron and Buprofezin before storage showed that Diflubenzuron has provided protection for the seeds for 10 months against $C$. chinensis (Linn). The insect evolution was failed on seeds treated with Triflumuron and Flucycloxuron. The impact of Flucycloxuron has continued for four months while the impact of Triflumuron reached 10 months. The Buprofezin was ineffective (Babu et al., 1991). Food treated with a concentration $10-100 \mathrm{mg} / \mathrm{kg}$ of Dofenapyn, Fenoxycarb, MV-678 and $\mathrm{RH}-20458$ was provided for the adult insects of southern cowpea beetle age 1-2 days. The results were evaluated for more than nine months and most of the tested compounds have shown high initial effectiveness during the first two weeks in which rate of egg-laying was reduced. The objectives of this study were to determine the impact of overlapping between the different concentration of growth regulator (cryomazine) and host type on the biological activity of southern cowpea weevils.

\section{MATERIALS AND METHODS}

The southern cowpea weevil C. maculatus (Bruchidae: Coleoptera) obtained from an entomological research laboratory farm was reared on peas (Pisum sativum), chickpeas (Cicer arietinum), mung beans (Phaseolus aureus) and cowpea seeds (Vigna sinensis). Adults of $C$. maculatus were placed in glass jar containing $1 / 2 \mathrm{~kg}$ seeds of each host and covered with a piece of cloth and bond with rubber firmly and then put in incubators, $30 \pm 2{ }^{\circ} \mathrm{C}$ and $50 \pm 5 \%$ R.H.
(Ishimoto et al., 1996). Cultures renewed after each generation by taking the newly emerged insects from pupae for construction of a new culture to conduct further studies.

IGR, cryomazine (Trigard) is used to control larvae of Diptera and Coleoptera. It used as a powder in water containing $750 \mathrm{~g} / \mathrm{kg}$ effective cyromazine (N-cyclopropyl 1, 3, 5-triazine-2, 4, 6-triamine) and sold under the names of the various commercial (Larvadex, Premix) classifies toxically within the Class III according to the classification of the World Health Organization (WHO). Solutions were prepared immediately prior to the experiments (Awad and Mulla, 1984).

Incubation period and egg hatchability were studied using 25 grams of seeds of peas, chickpeas, mung beans and cowpea seeds, which treated with three replicates for each concentration using the immersing method while in the control the seeds were immersed in water. Then the seeds were left to dry and transferred to disposable culture plastic of $7 \mathrm{~cm}$ in diameter and a height of 7 $\mathrm{cm}$. Ten pairs (male and female) of adult insects were added to the dried seeds. After $24 \mathrm{~h}$, the seeds with eggs were placed in Petri dishes and examined until all the eggs in the control were hatched to calculate the incubation period and hatching rate.

Larval and pupal duration where studied using 20 eggs for each duplicate, and after hatching, the larval stage was followed up by breaking the 2-3 seeds every three days and until the pupation of larvae to determine the larval stage and a success rate of the larvae to reach the pupal stage. Pupae were left in Petri dishes to determine the pupal stage and the proportion of adult emergence. For experimental designing and data analysis Factorial Complete Randomized Design (FCRD) was used and Duncan's Multiple Range Test to test the difference between the averages at $5 \%$ of probability (Daoud and Elyass, 1990).

\section{RESULTS AND DISCUSSION}

As shown in Table 1, increased cryomazine concentrations led to the increase in the average incubation period of $C$. maculatus eggs reared on all types of food used in the study in comparison with the control. The average incubation period reached 10.81, 11.44 and 11.63 days at a concentration of 1,3 and $5 \%$, respectively in comparison with 9.81 days of the control. The type of the cryomazine treated host affected the average of eggs incubation period that reached 12.13, $9.94,9.69$ and 11.94 days for each of the peas, chickpeas, cowpeas and mung beans, respectively (Table 2).

Statistical analysis results showed that the absence of significant differences between the cowpeas and chickpeas, and existence of the differences between them and mung beans and peas, as well as the absence of differences between mung beans and peas. This may be due to variation in the type of host. Shorter incubation period for eggs of the southern cowpea beetle was on beans followed by red kidney bean and cowpeas, and the longest incubation period was on peas (Gabouri, 2000).

Results showed that the impact of overlapping between the cryomazine concentrations and the host types on the incubation period of eggs, where the lowest average of incubation period is 9.25 days on cowpeas at a concentration of $1 \%$ and the highest is 13.25 days on mung beans when the concentrations of 3 and $5 \%$ (Table 3 ). 
Table 1. Studied parameters on the southern cowpea weevil, $C$. maculatus with different concentrations of cyromazine.

\begin{tabular}{lcccc}
\hline \multirow{2}{*}{ Parameter } & \multicolumn{4}{c}{ Concentrations } \\
\cline { 2 - 5 } & $\mathbf{1}$ & $\mathbf{3}$ & $\mathbf{5}$ & Control \\
\hline Incubation period & $10.81^{\mathrm{B}}$ & $11.44^{\mathrm{AB}}$ & $11.63^{\mathrm{A}}$ & $9.81^{\mathrm{C}}$ \\
Egg hatch ability & $38.56^{\mathrm{C}}$ & $21.06^{\mathrm{B}}$ & $13.13^{\mathrm{A}}$ & $78.75^{\mathrm{D}}$ \\
Larval duration & $27^{\mathrm{D}}$ & $28.75^{\mathrm{C}}$ & $28.92^{\mathrm{C}}$ & $25.42^{\mathrm{B}}$ \\
Pupation of larvae & $50.67^{\mathrm{C}}$ & $33.75^{\mathrm{B}}$ & $19.83^{\mathrm{A}}$ & $87.33^{\mathrm{D}}$ \\
Pupal duration & $9.08^{\mathrm{B}}$ & $9.67^{\mathrm{B}}$ & $10.08^{\mathrm{C}}$ & $8.75^{\mathrm{A}}$ \\
Adult emergence & $53.50^{\mathrm{C}}$ & $35.17^{\mathrm{B}}$ & 27.08 & $88.50^{\mathrm{D}}$ \\
\hline
\end{tabular}

Averages of similar characters refer to the existence of significant differences at the $5 \%$ level of probability.

Table 2. Studied parameters on the southern cowpea weevil, C. maculatus with different hosts

\begin{tabular}{lcccc}
\hline \multirow{2}{*}{ Parameter } & \multicolumn{3}{c}{ Host } \\
\cline { 2 - 5 } & Peas & Chickpeas & Cowpeas & Mungbeans \\
\hline Incubation period & $12.13^{\mathrm{A}}$ & $9.94^{\mathrm{B}}$ & $9.69^{\mathrm{B}}$ & $11.94^{\mathrm{A}}$ \\
Egg hatch ability & $25.88^{\mathrm{A}}$ & $43.75^{\mathrm{C}}$ & $43.56^{\mathrm{C}}$ & $38.31^{\mathrm{B}}$ \\
Larval duration & DAI & $29 \mathrm{~A}$ & $26.44^{\mathrm{B}}$ & $27.31^{\mathrm{A}}$ \\
Pupation of larvae & DAI & $49.06^{\mathrm{B}}$ & $53.75^{\mathrm{C}}$ & $40.88^{\mathrm{A}}$ \\
Pupal duration & DAI & $9.69^{\mathrm{A}}$ & $8.75^{\mathrm{B}}$ & $9.31^{\mathrm{A}}$ \\
Adult emergence & DAI & $50.1^{\mathrm{A}}$ & $55.31^{\mathrm{B}}$ & 47.69 \\
\hline
\end{tabular}

Averages of similar characters refer to the existence of significant differences at the $5 \%$ level of probability.

Data in Table 1 also shows that the increase in cryomazine concentrations significantly reduced the proportion of eggs hatching in comparison with the control. The hatching ratio reached $38.56,21.06$ and $13.13 \%$ at concentrations of 1,3 and $5 \%$. Fenoxycarb and Teflubenzuron were reported to be an efficient egg pesticide of $C$. pomonella (Lin) when spraying the pesticide on the plant before laying the eggs or on the newly laid eggs (Charmillot et al., 1989). Likewise, Alsystin was found to have high activity against eggs in addition to the first instar of larvae of Oryzaephilus surinamensis (Lin) and Rhizopertha dominica (Fab) where the percentage of eggs death reached $100 \%$ at a concentration of $5 \mathrm{ppm}$ (Main et al., 1982).

As shown in Table 2, the type of host food treated with cryomazine significantly reduced the percentage of hatching with an average 25.88, 43.75, 43.56 and $38.31 \%$ on each of the peas, chickpeas, cowpeas and mung beans, respectively. Also, the overlap between the cryomazine concentrations and the type of host food affect the percentage of hatching. Results showed that the least percentage of hatching $1.25 \%$ was on peas at a concentration of $5 \%$ and the highest $55 \%$ was on the mung beans at a concentration of $1 \%$ (Table 3). Ali et al. (2011) found that, humidity and starvation strongly affected egg hatchability under all conditions tested. At $35^{\circ} \mathrm{C}$, eggs took less time to hatch than at $30^{\circ} \mathrm{C}$ and there was a positive correlation between egg duration and R.H.

As shown in Table 1, all cryomazine concentrations used in the study led to the increase in the average duration of larval stage in comparison with the control. The average duration of the larval stage reached 27, $28.75,28.92$ days at concentrations of $1.3,5 \%$, respectively, while the control reached 25.42 days. Our study showed that there were significant differences at the level of probability of $5 \%$ in the average duration of duration of larval stage of insects reared on the cryomazine treated hosts between $1 \%$ concentration and the concentrations of 3 and $5 \%$ and the absence of significant differences in the larval stage between the concentrations of 3 and $5 \%$ and the existence of significant differences between all the concentrations and the control.

Housefly larvae reared on food treated with sublethal concentrations of cryomazine led to increase of average duration of larval stage (11.20 days), compared with 6.5 days of the control (Al-Abadi, 2001). Table 2 also shows that the type of host had reduced the average duration of larval stage in the presence of cryomazine. The average period was reached $29,26.44$ and 27.31 days for the larvae reared on chickpeas, cowpeas and mung beans, respectively. Results of the overlap between the concentrations and the type of host showed that there were no significant differences in the larval duration of all 
Table 3. Cryomazine concentration and host type effects on the incubation period, egg hatchability and larval duration of the southern cowpea weevil.

\begin{tabular}{clccc}
\hline Concentration & Host & Incubation period & Egg hatch ability & Larval duration \\
\hline 1 & & $12.5 \pm 0.75^{\mathrm{AB}}$ & $21.25 \pm 4.27^{\mathrm{CDEF}}$ & DAl \\
3 & \multirow{2}{*}{ Peas } & $12.5 \pm 0.29^{\mathrm{AB}}$ & $13.75 \pm 1.39^{\mathrm{BC}}$ & DAl \\
5 & $12 \pm 0.40^{\mathrm{ABC}}$ & $1.25 \pm 1.25^{\mathrm{A}}$ & DAl \\
Control & & $11.5 \pm 0.29^{\mathrm{BCD}}$ & $67.25 \pm 2.42^{\mathrm{J}}$ & $\mathrm{DAl}$ \\
& & $9.5 \pm 0.65^{\mathrm{E}}$ & $38.75 \pm 1.38^{\mathrm{H}}$ & $29.5 \pm 2.25^{\mathrm{A}}$ \\
3 & & $10.25 \pm 0.65^{\mathrm{DE}}$ & $28.75 \pm 1.75^{\mathrm{F}}$ & $30.00 \pm 2.12^{\mathrm{A}}$ \\
5 & Chickpeas & $10.75 \pm 0.75^{\mathrm{CDE}}$ & $23.5 \pm 1.12^{\mathrm{DEF}}$ & $29.75 \pm 2.19^{\mathrm{A}}$ \\
Control & & $9.25 \pm 0.48^{\mathrm{E}}$ & $84 \pm 0.91^{\mathrm{K}}$ & $26.75 \pm 1.31^{\mathrm{A}}$ \\
& & $9.25 \pm 0.63^{\mathrm{E}}$ & $39.25 \pm 4.11^{\mathrm{H}}$ & $25.5 \pm 1.71^{\mathrm{A}}$ \\
1 & & $9.75 \pm 0.48^{\mathrm{E}}$ & $25.5 \pm 2.10^{\mathrm{EE}}$ & $27.5 \pm 1.55^{\mathrm{A}}$ \\
3 & & $10.5 \pm 0.65^{\mathrm{CDE}}$ & $20.75 \pm 2.17^{\mathrm{CDE}}$ & $28.25 \pm 1.75^{\mathrm{A}}$ \\
5 & Cowpeas & $9.25 \pm 0.48^{\mathrm{E}}$ & $88.75 \pm 4.27^{\mathrm{K}}$ & $24.5 \pm 1.19^{\mathrm{A}}$ \\
Control & & & & \\
& & $12 \pm 0.41^{\mathrm{ABC}}$ & $55 \pm 2.04^{\mathrm{I}}$ & $26.75 \pm 1.70^{\mathrm{A}}$ \\
3 & & $13.25 \pm 0.48^{\mathrm{A}}$ & $16.25 \pm 3.15^{\mathrm{CD}}$ & $28.75 \pm 1.78^{\mathrm{A}}$ \\
5 & \multirow{2}{*}{ Mungbeans } & $13.25 \pm 0.48^{\mathrm{A}}$ & $7 \pm 1.08^{\mathrm{AB}}$ & $28.75 \pm 1.93^{\mathrm{A}}$ \\
Control & & $9.25 \pm 0.08^{\mathrm{E}}$ & $75 \pm 2.36^{\mathrm{G}}$ & $25.00 \pm 1.08^{\mathrm{A}}$ \\
\hline
\end{tabular}

Averages of similar characters refer to the existence of significant differences at the $5 \%$ level of probability.

DAl: Death of all insects.

the hosts where the highest period of larval stages reared on chickpea was 30 days at a concentration of $3 \%$ and less time those reared on cowpea was 25.5 days at a concentration of $1 \%$ (Table 3 ).

It is also clear from Table 1 that increased concentrations of cryomazine led to significantly reduction in the success rate of pupation where the percentage of pupation reached $50.67,33.75$ and $19.83 \%$ for concentrations of 1,3 and $5 \%$, respectively in comparison with the control (87.33\%). Housefly eggs treated with sublethal concentration of cryomazine showed reduction in the proportion of larvae $51 \%$ the pupal stage that reached $51 \%$ compared to $77 \%$ in the control (Al-Abadi, 2001). Metwally et al. (1972) found that Hydroprene was highly active to prevent the transformation of Trogoderma granarium Everts. As shown in the Table 2, the type of host treated with cryomazine had a significant effect on the average of success rate of pupation 49.06, 53.75, $40.88 \%$ for chickpeas, cowpeas and mung beans, respectively.

Results showed that the overlap between the cryomazine concentrations and the type of host affect the success rate of the pupation. The results showed that there were significant differences $(P>5 \%)$ as the lowest rate reached $13 \%$ at a concentration of $5 \%$ on mung beans and the highest $60 \%$ on the beans at a concentration of $1 \%$. For chickpeas treated with cryomazine the insects was unable to complete the larval stage at all concentrations used in the study, while the average duration of larval stage 30 days and pupation proportion of $75.25 \%$ in the control (Table 4).

For pupal duration and adult emergence percentage, Table 1 shows that all cryomazine concentrations used in the study led to the increase in the average duration of the pupal stage in comparison with the control, where the period reached $9.08,9.67,10.08$ days for each of the concentrations of 1,3 and $5 \%$, while for the control 8.75 days. Results showed that the absence of significant differences between the concentrations of 1 and $3 \%$, while there were significant differences between them and the concentration of $5 \%$, as well as the existence of significant differences between all the concentrations and the control. Al-Abadi (2001) pointed to an increase in the average of pupal stage of the housefly whose eggs was treated with cryomazine, amounting to 7.2 days compared with 5 days for pupae of the control.

Table 2 also shows that the type of host treated with cryomazine had a significant effect in the average duration of the pupal stage reaching $9.69,8.75,9.31$ day for pupae reared on chickpeas, cowpeas and mung beans, but for the impact of overlap between the cryomazine concentrations and the type of host in the duration of pupal stage bringing the average longest period of the pupal stage reared on the host treated with concentration of $5 \%$ of cryomazine 10.50, 9.50 and 10.25 days in each of the chickpeas, cowpeas and mung beans, respectively, while the average shortest duration of the pupal stage in insects reared on the hosts with concentration of $1 \%$; $9.5,8.25$ and 9.50 days for each of chickpeas, cowpeas and mung beans, respectively 
Table 4. Cryomazine concentration and host type effects on pupation of larvae, pupal stage duration and adult emergence of the southern cowpea weevil.

\begin{tabular}{|c|c|c|c|c|}
\hline Concentration & Host & Pupation of larvae & Pupal stage duration & Adult emergence \\
\hline 1 & \multirow{4}{*}{ Peas } & DAI & DAI & $\overline{D A I}$ \\
\hline 3 & & DAI & DAl & DAl \\
\hline 5 & & DAl & DAl & DAl \\
\hline Control & & DAl & DAl & DAl \\
\hline 1 & \multirow{4}{*}{ Chickpeas } & $53.50 \pm 1.32^{\mathrm{H}}$ & $9.5 \pm 0.65^{\mathrm{ABC}}$ & $52.50 \pm 2.1^{\mathrm{EF}}$ \\
\hline 3 & & $33.00 \pm 1.08^{\mathrm{E}}$ & $10.25 \pm 0.48^{\mathrm{AB}}$ & $34.00 \pm 2.04^{C}$ \\
\hline 5 & & $21.5 \pm 1.55^{\mathrm{B}}$ & $10.5 \pm 0.65^{\mathrm{A}}$ & $26.75 \pm 3.07^{\mathrm{B}}$ \\
\hline Control & & $88.25 \pm 1.49^{G}$ & $8.5 \pm 0.63^{\mathrm{BC}}$ & $87.5 \pm 1.19^{\mathrm{H}}$ \\
\hline 1 & \multirow{4}{*}{ Cowpeas } & $60.00 \pm 0.41^{1}$ & $8.25 \pm 0.73^{C}$ & $57.5 \pm 2.10^{\mathrm{F}}$ \\
\hline 3 & & $40.00 \pm 0.82^{F}$ & $8.75 \pm 0.48^{\mathrm{ABC}}$ & $39.25 \pm 1.93^{\mathrm{D}}$ \\
\hline 5 & & $25.00 \pm 0.82^{C}$ & $9.50 \pm 0.65^{A B C}$ & $31.00 \pm 2.94^{A B}$ \\
\hline Control & & $90.00 \pm 0.82^{G}$ & $8.5 \pm 0.65^{\mathrm{BC}}$ & $93.50 \pm 1.32^{\mathrm{J}}$ \\
\hline 1 & \multirow{4}{*}{ Mungbeans } & $38.50 \pm 1.55^{\mathrm{F}}$ & $9.50 \pm 0.65^{\mathrm{ABC}}$ & $50.50 \pm 2.47^{\mathrm{E}}$ \\
\hline 3 & & $28.25 \pm 2.01^{\mathrm{D}}$ & $10.00 \pm 0.41^{\mathrm{ABC}}$ & $32.25 \pm 1.31^{\mathrm{AB}}$ \\
\hline 5 & & $13.00 \pm 0.91^{\mathrm{A}}$ & $10.25 \pm 1.03^{\mathrm{AB}}$ & $23.50 \pm 2.95^{\mathrm{A}}$ \\
\hline Control & & $83.75 \pm 1.49^{J}$ & $9.25 \pm 0.48^{\mathrm{ABC}}$ & $84.5 \pm 1.04^{\prime}$ \\
\hline
\end{tabular}

Averages of similar characters refer to the existence of significant differences at the $5 \%$ level of probability. DAl: Death of all insects.

(Table 4). Other factor may be effects on the pupal duration as Ali et al. (2011) stated that, at $30^{\circ} \mathrm{C}$ pupal duration decreased with increasing r.h. while at $35^{\circ} \mathrm{C}$ there was a slight increase. However, the duration at $35^{\circ} \mathrm{C}$ was always shorter than at $30^{\circ} \mathrm{C}$.

As shown in Table 1, the increase of the cryomazine concentration resulted in a clear and significant reduction in the average rate of adult emergence in comparison with the control where it reached 53.5, 35.17 and $27.08 \%$ for concentrations of 1,3 and $5 \%$ in comparison with the control $88.5 \%$. The emergence percentage of housefly adult from eggs treated with sublethal concentrations of cryomazine was reduced where it reached $30 \%$ in comparison with $63.50 \%$ of the control (Al-Abadi, 2001). Diflobenzuron was found to reduce the emergence of adults Pectinophora gossypiella Saund when larvae reared on food treated with different concentration of Diflobenzuron and related compounds, whereas, concentrations more than $100 \mathrm{ppm}$ completely inhibited the emergence of adults (Flint et al., 1987).

Table 2 shows that the host type significantly affect the adult emergence percentage that reached $50.19,55.31$ and $47.69 \%$ for chickpeas, cowpeas and mung beans, respectively. The overlap between the cryomazine concentrations and the host type showed that there were significant differences for all concentrations and host types used in the study, where the lowest rate for the adult emergence reached 23.50 on mung beans at concentration of $5 \%$, and the highest rate of reached $57.50 \%$ on cowpea at concentrations of $1 \%$ (Table 4).
For the pupal durtion and adult emergence on peas, the insects were unable to complete their life cycle with an average of pupal duration (12.5 days) and the average of adult emergence $(72.25 \%)$ in control. In Obliquebanded Leafroller Choristoneura rosaceana (Harris), the pupation and adult emergence was significantly delayed at Pyriproxyfen concentrations higher than $1 \mathrm{ppm}$ (Sial and Brunner, 2010). Ali et al. (2011) study the influence of two temperatures $\left(30\right.$ and $\left.35^{\circ} \mathrm{C}\right)$ and three humidities $(40,60$ and $80 \%$ R.H.) on the adult emergence and they stated that, there was $100 \%$ emergence of adults from pupae under all test conditions except 40 and $60 \%$ R.H. at $35^{\circ} \mathrm{C}$ where it fell to about $90 \%$.

The outcome results showed the increasing cryomazine concentration led to the increase in the average incubation period of eggs and low hatching rate. Increasing cryomazine concentration not only led to the increase in the average duration of larvae and pupae of insects bred to all nutritional hosts except peas where the insect was unable to complete its life cycle but also led to reduction in the percentage of pupation and adult emergence.

\section{ACKNOWLEDGMENT}

Authors extend their appreciation to the Deanship of Scientific Research at king Saud University for funding the work through the research group project No. RGP- VPP028. 


\section{REFERENCES}

Al-Abadi AKI (2001). Biological effect of some insecticides on the house fly Musca domestica (Muscidae: Diptera). Master thesis, College of Agriculture and Forestry, Mosul University, Mosul, Iraq.

Ali MF, Mashaly AMA, Mohammed AA, Abo El -Magd MM (2011). Effect of temperature and relative humidities on biology of the carpet beetle Attagenus fasciatus (Thunberg) (Coleoptera: Dermestidae). J. Stored Prod. Res., 47: 25-31.

Arthur FH (1996). Grain protectants: current status and prospects for the future. J. Stored Prod. Res., 32: 293-302.

Awad TI, Mullam MS (1984). Morphogenetic and histo pathological effects induced by the insect growth regulator Cyromazine in Musca domistica L Diptera: Muscidae. J. Med. Entomol., 21: 419-426.

Babu TR, Hussaini SH, Sriramulu M, Siddiqui MKH (1991). Effect of inert clay and insect growth regulators on the development of $C$. chinensis $\mathrm{L}$. and the germination of mungbean seed Vigna radiata ( $\mathrm{L}$. Wikzek) Trop. Sci., 51: 217-221.

Charmillot PJ, Bloesch B, Benz M (1989). Control of codling moth Cydia pomonella (L) with Fenoxycarb and Teflubenzuron. Revue Suisse Vitic Arboric Hortic., 21: 187-193.

Credland PF, Dick M (1987). Food consumption by larvae of three strains of Callosobruchus maculatus (F). J. Stored Prod. Res., 23: 31-40.

Daglish GJ, Erbacher JM, Eelkema M (1993). Efficacy of protectants against C. phaseoli (Gyll) and C. maculatus (Fab) Coleoptera: Bruchidae in mungbeans J. Stored Prod. Res., 29: 345-349.

Daoud KM, Elyass ZA (1990). Statistical methods for agricultural research, National Library of Printing and Publishing, University of Mosul, Iraq.

Elazawe AF, Quado IQ, Al Haydary HS (1990). Economic insects. Dar Al-Hekma Press, University of Baghdad, Iraq. Fields, P.G., 1992. The control of stored-product insects and mites with extreme temperatures. J. Stored Prod. Res., 28: 89-118.

Flint HM, Smith RL, Noble JM, Shaw D, Demilo AB, Khalil F (1987). Laboratoray tests of Diflubenzuron and four analogues against the pink bollworm and a Field Cage test with Diflubenzuron and E1-494 for control of the pink bollworm and cotton leaf perforator. J. Econ. Entomol., 71: 616-619.

Fujii K, Gatehouse AMR, Johnson CD, Mitchel R, Yoshida T (1990). Bruchids and legumes: Economics, ecology and coevolution. Kluwer Academic publishers, London.

Gabouri IAH (2000). Food preference of the Southern cowpea weevil, Callosobruchus maculatus (F.) (Bruchidae: Coleoptera) and the effect of different temperatures on the biology, Master thesis, Faculty of Agriculture and Forestry, University of Mosul, Iraq.

Hagstrum DW, Subramanyam BH (2006). Fundamentals of StoredProduct Entomology. AACC International, St. Paul.

Haines CP (1981). Insects and arachnids from stored products: a report on specimens received by the tropical stored products centre 19731977. Report of the tropical products institute. L 54: iv + p. 73.

Howe RW, Currie JE (1964). Some laboratory observations on the rates of development mortality and oviposition of several species of Bruchidae breeding in stored pulses. Bull. Entomol. Res., 55: 437477.
Ishimoto M, Sato T, Chrispeels MJ, kitamura K (1996). Bruchid resistance of transgenic azuki bean expressing seed amylase inhibitor of common bean. J. Entomolgia Experimentalis et Applicata, 79: 309-315.

Khallak F (1990). Influence of Dimilin on reproduction and development of the four spotted cowpea weeviyl C. maculatus (F) IzvestiyaeTimiryazevskoi-skokhozyais trennoi Akademi, 4: 211-214.

Labeyrie V (1981). Vaincre la carence proteique par le développement des légumineuses alimentaires et la protection de leurs récoltes contre les bruches. Food Nutr. Bull., 3: 24-38.

Main LAL, Miks Mulla (1982). Biological activity of IGRs against four stored-product. Coleopteras. J. Econ. Entomol., 75: 80-85.Metwally MM, Sehnal F, Landa V (1972). Reduction of fecundity and control of the khapra beetle by Juvenil hormone mimics. J. Econ. Entomol., 55: 1603-1605.

Oberlander H, Silhacek DL, Shaaya E, Ishaaya I (1997). Current status and future perspectives of the use of insect growth regulators for the control of stored product insects. J. Stored Prod. Res., 33: 1-6.

Pajni HR (1965). Bioassay of insecticides relative toxicity of films of different insecticides against the adults of $C$. maculatus ( $F$.). Res. Bull. Panjab University, 16: 341-559.

Richmond JA, Demilo AB, Thomas HA, Borkovec AB (1978). Mortality and sterility of southern pine beetles treated with chemosterilants and growth regulators. J. Georgia Entomol. Soc., 13: 237-240.

Saplina C (1980). C. maculatus (F) Zashchita Rastenii, 7: 41.

Shinoda K, Yoshida T (1985). Field biology of the azuki bean weevil, Callosobruchus chinensis (L) (Coleoptera, Bruchidae). 1. Seasonal prevalence and assessment of field infestation of aki-azuki, autumn variety of Phaseolus angularis W. Japanese J. Appl. Entomol. Zool., 29: 14-20.

Shinoda K, Yoshida T (1990). Life history of the azuki bean weevil, Callosobruchus chinensis L. (Coleoptera: Bruchidae), in the field. In Bruchids and legumes: Economics, Ecology and Coevolution (K. Fujii ed.). Kluwer Academic Publishers, Dordrecht, pp. 149-159.

Shinoda K, Yoshida T, Okamoto T (1991). Two wild leguminous host plants of the azuki bean weevil, Callosobruchus chinensis (L.) (Coleoptera: Bruchidae). Appl. Entomol. Zool., 26: 91-98.

Shinoda K, Yoshida T, Igarashi H (1992). Population ecology of the azuki-bean beetle, Callosobruchus chinensis (L), (Coleoptera, Bruchidae) on 2 wild leguminous hosts, Vigna angularis var nipponensis and Dunbaria villosa. Appl. Entomol. Zool., 27: 311-318.

Sial AA, Brunner JF (2010). Lethal and Sublethal Effects of an Insect Growth Regulator, Pyriproxyfen, on Obliquebanded Leafroller (Lepidoptera: Tortricidae). J. Econ. Entomol., 103: 340-347.

Singh KN, Srivastava BP (1980). Studies of the efficacy and extent of residue of phosphine in stored pulses. Pesticides, 14: 32.

Tuda M, Chou LY, Niyomdham C, Buranapanichpan S, Tateishi Y (2005). Ecological factors associated with pest status in Callosobruchus (Coleoptera: Bruchidae): high host specificity of nonpests to Cajaninae (Fabaceae). J. Stored Prod. Res., 41: 31-45.

Vazirianzadeh B, Jervis MA, Kidd NAC (2007). The Effects of Oral Application of Cyromazine and Triflumuron on House-Fly Larvae. Iran J. Arthropod. Borne Dis., 1: 7-13. 